\title{
THE CURRENT STATE OF RUSSIAN REGIONAL INTERNET MEDIA (ON THE EXAMPLE OF THE REPUBLIC OF TATARSTAN)
}

\author{
Tatiana A. Nagovitsyna ${ }^{1}$ \\ Ramis R. Gazizov
}

\begin{abstract}
The paper concerns the determination of the state of development of the Internet mass media (on the example of the Republic of Tatarstan). It considers the issues of formation and the regional peculiarities of this type of media environment, summarizes the experience of the Internet media of the Republic of Tatarstan. The authors focus special attention on multimedia, as a factor in the

Tatarstan remains among the most reading regions in Russia. As of today in the given region of Russia there is registered 1067 mass-media. In connection with the development of the Internet media, which today determine the leading trends in the functioning of all the mass media, it seems to us necessary to consider the peculiarities of the Internet media of the Republic of Tatarstan.
\end{abstract} development of networked media at the present stage. The specifics of the Internet media has significantly changed the nature of the presentation of materials, the work of journalists, the target audience, as well as the system of functioning of the media in general. The authors analyzed the nature of the influence of multimedia on the features of functioning of regional networked media. In recent years, the Republic of

Keywords: Internet media, the Republic of Tatarstan, multimedia, online space. target audience, regional media.

\section{INTRODUCTION}

Over the past 10 years, the Republic of Tatarstan remains among the most reading regions in Russia. Currently, in the given region of Russia

\footnotetext{
${ }^{1}$ Kazan (Volga region) Federal University, Kremliovskaya str, 18,420008, Kazan, Russian Federation

${ }^{2}$ Kazan (Volga region) Federal University, Kremliovskaya str, 18,420008, Kazan, Russian Federation
} 
there is registered 1067 mass media. In connection with the development of the Internet media, which today determine the leading trends in the functioning of all the media, it seems to us necessary to consider the peculiarities of the Internet media of the Republic of Tatarstan.

To date, two positions concerning the role and essence of the Internet have been defined in the theory: anthropomorphism and mediamorphism. Anthropomorphism goes back to the ideas of organ projection, according to which the tools and things created by man with the help of tools are the projection of his organs (M. McLuhan [1]). Mediamorphism, on the contrary, assumes that in the global networks there emerge fundamentally different ones from human organization (M. Castells [2], E. Toffler [3], etc.) due to the action of systemic and synergistic mechanisms. The tension between these two positions, according to the author, will determine the strategy of development of information and communication means.

The specifics of the Internet media has significantly changed not only the nature of the presentation of materials, the specifics of the work of journalists, but also the whole system of functioning of the media in general. The
Internet has become an integral part of modern civilization. Strikingly breaking into the spheres of all social life, it generates new forms of communication and learning, commerce and entertainment [4].

The studies about the development of Internet journalism highlight, today, the idea that the Internet media are a new variety of the media or an integral part of the media system is becoming more and more clear. Comparison of traditional and on-line media reveals a number of undisputed advantages of the mass media functioning in the global network.

It is important that the networked media are not limited to space and time in the same way as traditional media [5]. Besides, the advantage of mass media on the Internet is almost unlimited circulation and the relative cheapness of the work of employees [6].

\section{METHODS}

In Russia in general, and in the Republic of Tatarstan in particular, the formation of the Internet media system goes through certain stages, including the search for its audience. If in 2005 the Internet-press of Tatarstan had less than 
ten actual networked media and about 50 websites close to understanding traditional media on the Internet, then, starting in 2007, the number of electronic media has significantly increased. It is encouraging to note that the quality of these publications has also been improved. Since 2007, the site of the urban news "ProKazan ru"has been appearing. Today, this edition is the third largest by the number of views, conceding "BUSINESS Online" and "Kazanfirst".

At the end of 2014online edition "Real Time" began to come. In our opinion, the rubric "All Analytics" and "Photo Gallery" are of interest. The audience is the readers aged from 18 to 55 years old. Moreover, men read this edition more than women

On-line offices of the newspapers "Business Quarter”, "Kazan Gazette”, "Evening Kazan”, “Arguments and Facts" and "Intertat.ru" [7] can be referred to the category of electronic versions. Their characteristic feature is the wide coverage of city, republican and federal news.

It is necessary to distinguish another category of on-line media of the Republic of Tatarstan. It includes the portals "E-kazan.ru", "ProKazan.ru" and the site "Kazan24.ru" [8]. The pages of these publications cover mainly the news of Kazan. They write enough about the city events and they often contain many details. Sometimes journalists turn to a certain topic more than once. Media content of these mass media is significantly expanded, thanks to photos, audio recordings and video recordings.

\section{RESULTS}

According to the results of the rating of media resources of the Republic of Tatarstan for the third quarter of 2016, according to the company "Medialogy", the first positions for the last several years is occupied by business electronic newspapers "BUSINESS Online", the second - by information agency "TatarInform", and the third - by Internet resource "Realnoevremya.ru" [6]. Moreover, "BUSINESS Online" and "Tatar-Inform"have been occupying the first positions for the past few years [9]. Carrying out a structural analysis of the materials of these newspapers and the news agency for the period from January 1 till December 31, 2016, we found that the newspaper "BUSINESS Online", as stated in the title, specializes in representing the 
materials on business topics. However, it does not restrict itself only to this topic. Here you can find materials from almost all spheres of Tatarstan's public life: politics, culture, education, science, sports, etc.

The appearance of completely original Internet publications - the portal "Inkazan.ru" and the Internet magazine «Инде» testifies to a new stage in the development of electronic media in Tatarstan. Internet magazine «Инде» specializes in photographs. On-the spot snap shots are accompanied by small comments[10].

The Internet magazine«Инде» can serve not only as an example of the representation of the materials for youth, but also as an example of the organization of feedback - newspaper reader - newspaper. Practically there are no a comment of the readers that would remain without attention of journalists.

Among the specialized online media in the Republic of Tatarstan, publications specializing in small business, automobiles and construction are popular.

One more characteristic feature of the Internet publications of the Republic of Tatarstan is multimedia. According to A. A. Nikitenko, interactivity, multimedia, intertextuality are the determining typological characteristics of online publications" [11]. I. Kiria writes that the multimedia language is interactive, because it allows using various variants and various semantic schemes to obtain information using the data by nature itself to the person's opportunity”[12].

From the point of view of $\mathrm{M}$. McLuhan [13], those intensive details that characterize modern visual series are a sign of already automatic, and not more archaic, machine, that is the photographic technology. The essence of the changes that occur with visuality can be explained via the concept "virtual". In this case, the referent of the image, that is, the real thing, is deprived of its status, and the paramount importance is given the image itself.

\section{DISCUSSION}

In recent years, Russian scientists pay enough attention to the Internet media issues. However, this cannot be said about the Internet media of the regions of the Russian Federation and the Republic of Tatarstan in particular. A. A. Netikenko, I.Kiriya, etc. studied the general multimedia issues of 
the Internet media. The necessity to determine the place of on-line media in the system of modern mass media called forth the turn to the works by A.I. Akopov, R.P. Ovsepyan, E.P. Prokhorov, L.L. Resnianskaya, I.D. Fomicheva, M. V. Shkondin.

In considering the problems of the functioning of the Internet media, it is necessary, from our point of view, to refer to the work by E. Dennis and J. Merrill, I. I. Zasursky, A.I. Chernykh.

It should be noted the works that most fully reflect the principles of working the network media and their features. These are the studies by A.A. Kalmykov and L. A. Kokhanova, V.V. Kikhtan, M.M. Lukina and I.D. Fomicheva, E.P. Prokhorov.

Among the works dealing the regional Internet media of the Republic of Tatarstan, it is necessary to cancel the works by T. A. Nagovitsina, R. R. Gazizov, V. Z. Garifullin, and others.

\section{CONCLUSION}

Thus, we came to the conclusion that Tatarstan, as well as throughout Russia, has accumulated quite a lot of experience in the work of the Internet media. The very fact of the appearance of mass media, the work of which is based purely on the use of multimedia content, is evidence of the wide development of the republican Internet publications in the field of convergence.

Such elements of multimedia as photos and video materials on the virtual pages of "BUSINESS Online" appear in almost all the categories. Video, as a multimedia function, gives the reader an opportunity to penetrate the problem. The materials of this publication are distinguished by their large volume and profundity of presentation.

In the context of studying the multimedia problem on the Internet mass media of the Republic of Tatarstan, it is also worth highlighting the portal "Inkazan.ru" in which the photo-reports are taken as a basis for the media addition

We believe that the role of the multime

diafactorindevelopmentandtheplaceforth eformulaoftheInternetmediarequiresfurt herinvestigation. Studying it as one of the features of the networked mass media will make it possible to say that for today the prospect of the development of Russian federal and regional Internet 
media is precisely the wide application of new approaches to multimedia.

\section{The Conflict of Interests}

The authors confirm that the presented data do not contain any conflict of interests.

\section{Acknowledgements}

The work is performed according to the

Russian Government Program of Competitive Growth of Kazan Federal University.

\section{REFERENCES}

McLuhan M., Hutchon K., McLuhan E.

- City as Classroom: Understanding Language and Media. The Book Society of Canada Limited, 1977.

End of Millennium: The Information Age: Economy, Society, and Culture Volume III Manuel Castells 0.000 ISBN: 1-405-19688-2 2010. Wiley-Blackwell

Toffler, E., Toffler, X. Revolutionary Wealth, 2006.

Gazizov R.R, Nagovitsyna T.A., Features of manipulative technologies in Russian political discourse (on the example of the tatarstan republic mass media)//Journal of Organizational Culture, Communications and Conflict. 2016. - Vol.20, Is.SpecialIssue2. - P. 1418.

Margarita G. Bogatkina, Elena S. Doroschuk and Ramis R. Gazizov Converging Innovations in the Modern Humanitarian Science // The Social Sciences 10 (7) : 1932-1934. 2015.

Nagovitsyna T.A, Gazizov R.R., Mass media of the republic of tatarstan penal system: Social, psychological and communicative aspects//Journal of Organizational Culture, Communications and Conflict. - 2016. Vol.20, Is.SpecialIssue2. - P.9-13.

Elena S. Doroschuk, Tatiana S. Staroverova. Online Representations of Media in Modern Information Space of Russia Region // International journal of humanities and cultural studies Special Issue August 2016. P.174-180.

Vasil Zagitovich Garifullin, Ruzil Galievich Mingalimov. Tatar journalism transformation vectors // Journal of Language and Literature, ISSN: 2078- 
0303, Vol. 6. No. 3. Iss.1, August, 2015.

Pp. 192-194.

Vasil Zagitovich Garifullin, Ruzil

GalievichGarifullin, V.Z., Sabirova, L.R. The rise and development of economic journalism in the republic of tatarstan // Journal of Language and Literature. 2015. 6 (3). Pp. 214-217.

Vasil Zagitovich Garifullin, Linar Rustamovich Zakirov. Functioning of civic/citizen journalism in the media space of the Republic of Tatarstan // The Turkish Online Journal of Design, Art and Communication. TOJDAC November 2016 Special Edition. Pp.2322-2326.

NikitenkoA.A. Interactivity, Multimedia, Intertextuality as the Determining Typological Features of Network Publications .- The Journal of VSU. - SeriesPhilology. Journalism. 2009. - №1. - M.: VSUPress.

KiriyaI. WhatisMultimedia? // JournalismandConvergence:Whyand How do the Traditional Mass Media Converge into the Multimedia. M.:High School of Journalism, 2010.
McLuhan G.M. Understanding Media: The external expansion of rights. M., 2003. 